\title{
THE FEATURES OF THE USE OF GIS TECHNOLOGIES FOR MONITORING OF THE SITUATION OF MAIN WATER LINES IN AZERBAIJAN
}

\author{
M.H.Gojamanov ${ }^{\mathrm{a}}$, Ch.Z.Qurbanov ${ }^{\mathrm{a}}$ \\ ${ }^{a}$ Baku state University, Geographical Faculty, Department of Geodesy and Cartography, \\ 23, Z. Khalilov str, Baku, Azerbaijan, AZ 1048 \\ mgodja@yandex.ru
}

Technical Commission II

KEYWORDS: Environment, GIS, Monitoring, Image, Modeling, Water supply

\begin{abstract}
:
The characteristic feature of the unified system of water supply of Azerbaijan is the large spatial remoteness between the main water sources (Greater and Small Caucasian mountains) and water-using economic areas ( Baku, Ganja, Sumgait etc).

When operating the pipelines arise accident and emergency situations, which are connected with interaction of the technological elements of the water supply and the natural environment. Often this process is a violation of dynamic equilibrium, and is accompanied by activation of dangerous natural and natural-anthropogenic processes that have a negative impact on the condition of pipelines. Given that in Azerbaijan the basis of the water supply network was put in the XIX century, it is necessary to pay close attention to the assessment of the ecological situation of main lines of water pipelines, i.e. to conduct their monitoring.

Ensuring the reliability of existing and planned pipelines, a comprehensive study of the impacts on the natural environment during the construction and operation of the technical facilities, the organization of system of information and analytical monitoring requires a comprehensive attract the materials of the aerospace sensing and GIS technologies.

In this paper describe the work experience and are the results of monitoring of pipelines of water supply in Azerbaijan.
\end{abstract}

\section{INTRODUCTION}

Accidents of various types and size and emergency situations appear during exploitation of water supply natural - technical system. The main reasons are related to the interrelation of the system's technological elements with natural environment. In most cases, this process occurs on the background of disturbance of dynamic balance. Therefore, this is accompanied by the activation of natural and technology-related. The mentioned have negative effect on water supply pipelines as well which affects environment.

During investigation, selection and construction as well as exploitation of highways where water supply pipelines pass through, direct and indirect intensive impact on pipelines, natural resources, mineral deposits, ground and relief, soil, water, air, life, flora occurs apart from impacts of natural environment which cause the significant change of natural constituents and worsening of economic conditions as well as socio-economic conditions.

\section{MAIN BODY}

Monitoring of geo-ecological condition of water supply pipeline network (natural-technical complex) means the investigation of dynamic balance between natural and technological elements of the system (Gojamanov, M., 2006a. ) . For objective evaluation of geo-ecological condition of pipeline system, adequate and complete information should be obtained and the opportunity for formation of mathematical model reflecting interdependence of elements of natural and technical system especially emergency situation should be provided. Consequently, the necessity for development of special method and techniques with a view to evaluate geo-ecological condition of major water supply pipeline natural and technical system and processing of relevant technologies with a view to eliminate or reduce accident consequences arises. The importance and applicability of conduction of monitoring in space-time aspects on major water supply pipeline natural and technical system is confirmed (Figure 1).

Reliable arrangement of the work on the existing and projected major pipeline, research of factors affecting environment in the issue of construction and exploitation of technical apparatus, creation of conditions for the most effective methods natural resource use, organization of information analysis system, all the mentioned require aerospace remote investigation methods and GIS technology. However, analysis suggests that remote sensing data and techniques are not used efficiently for the solution of above mentioned issues. Increased use of aerospace planning materials during development of cartographic products and creation of specialized geographic information system is possible. Such disorders are especially observed in the study of impact of different technical construction complex on natural 


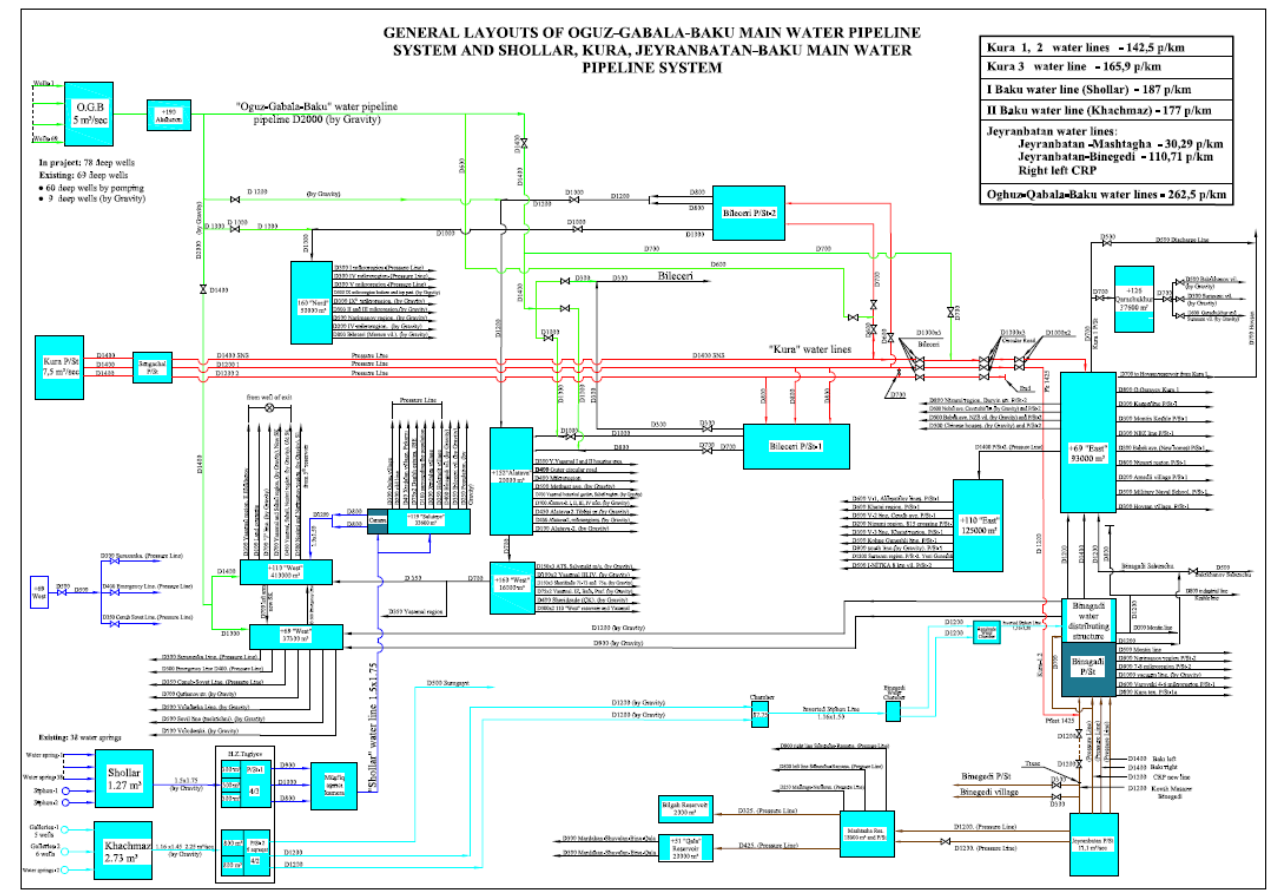

Figure 1. The main water lines in Azerbaijan

environment and optimization of natural resource use. Improve of the aerospace information usage efficiency during analysis of plane state of natural-technical system's line structures enables to warn about hazardous emergency situations of different complex structure with possibility to occur or take appropriate measures on reducing effects of currently existing negative events(Gojamanov, M., 2009).
It is known that wide major water supply pipeline system connecting water sources and water consumers laid for water supply purposes was created in the territory of our country especially big cities (Baku, Ganja, Sumgait etc.). These pipelines pass through the regions of different physicalgeographical conditions, geological - geomorphologic structure, seismic-tectonic activity (Fig.2, Fig. 3).

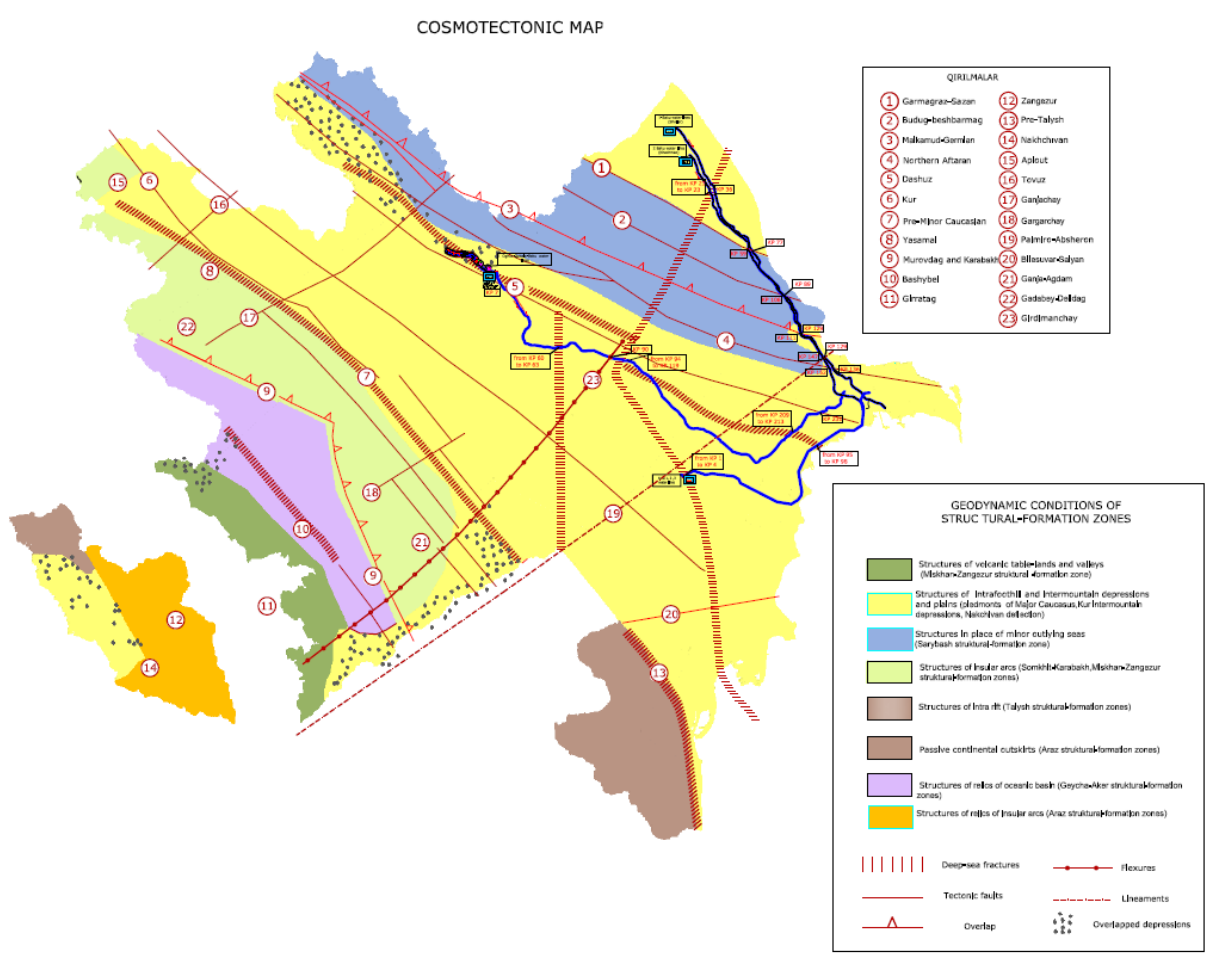

Figure 2. Physical-geographical conditions, geological - geomorphologic structure, seismic-tectonic activity in Azerbaijan 
Therefore, the necessity of organization and conduction of constant and monitoring of their state in space-time aspect arises. Geographic Information System (GIS) is of great importance during monitoring.

The development of the new technologies collecting, processing and storing information and coinciding with capabilities of other modern technical measurement equipments related to the monitoring of major pipeline on the basis of GIS provides the new aerospace-geodesic monitoring at a high quality. This plays an essential role in the implementation of overall assessment of plan-height state of major water supply pipeline network facilities, the study of the impact of water supply network on environment and alternatively, the impact of natural processes on major pipeline as well as:
- acquisition of the most comprehensive data on the degree, level of interrelation of natural environment components with engineering constructions;

- Substantiation of efficiency of solution projects on engineering security of natural environment and water supply facilities in collected database;

- is important in the prevention of development of accidents and emergency situations occurred in water supply facilities in the further stage.

Consequently, the necessity for investigation and determination of specificity of interrelation between water supply system and environment arises.

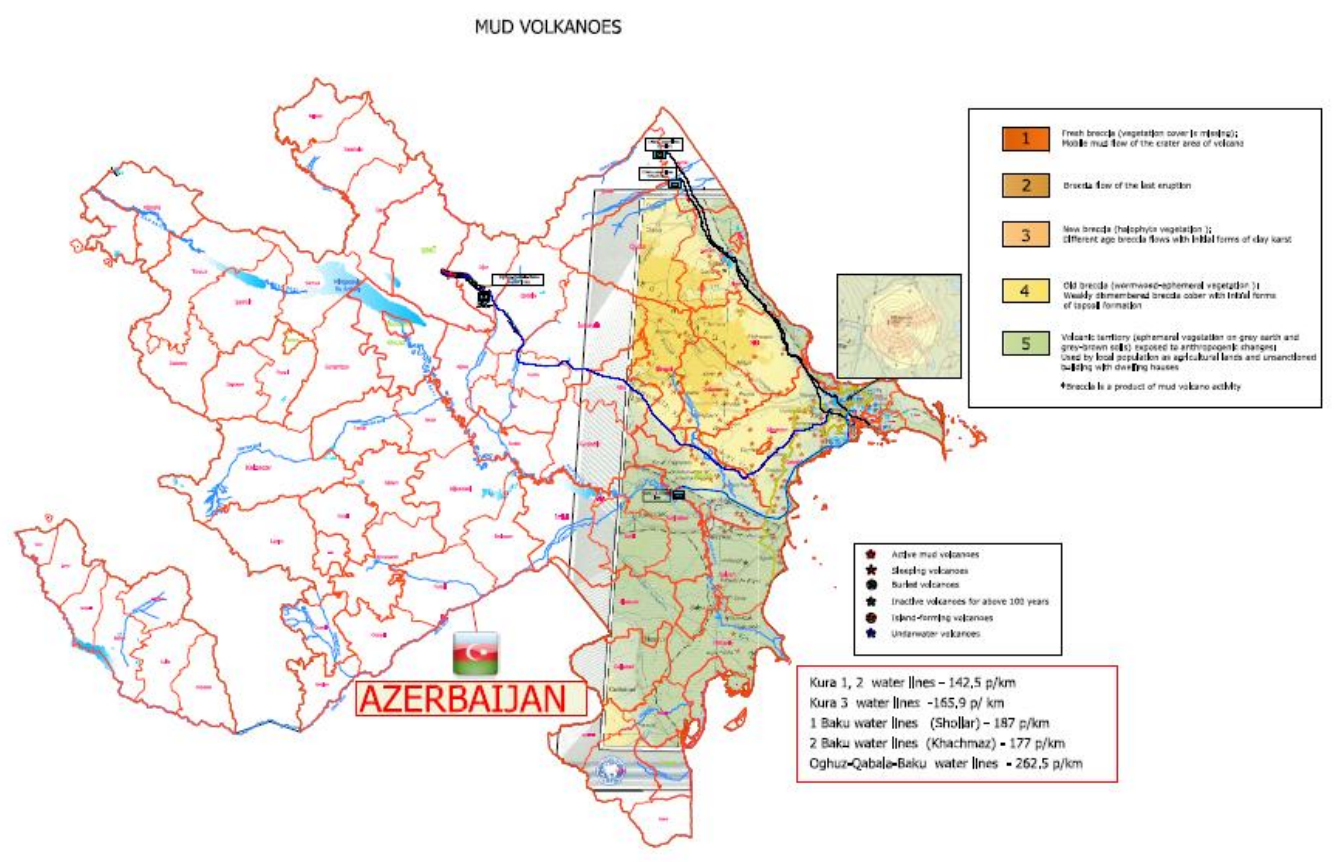

Figure 3. Mud volkanoes in Azerbaijan

In this regard, the development of complex assessment techniques and methods of Azersu major water supply lines from space-time aspect would be essential. The following issues should be solved for achievement of objectives within the confines of the mentioned problem:

1. Preparation of office processing technologies of geodesycartography and aerospace as well as remote sensing research data with special software for service and its testing; as well as assessment of level of informative value of this information for monitoring of major water supply lines state.

2. Thematic analysis of the territories that the major pipeline route pass through on the basis of results of interrelation between technical constructions and natural territorial complexes and condition by taking the factor of hazardous event occurrence into consideration.

3. Preparation of recommendations on optimal placement of water supply line route on the basis of assessment of displacement, dynamics of major pipelines, forecast on balance (stability) and the use of developed methods and mathematical models

4. Development of structure and content of special geoinformation system database to be created for data support of monitoring of major pipelines. 5. Formulation of information-mathematical models for 
realization of specific GIS project for investigated major pipelines and monitoring of operating pipelines as well as projected pipelines forecast.

The following methods and technological schemes in the solution of determined issues:

- Thematic cartography, aerospace monitoring, generalization methods of analysis and results for assessment of natural territorial complex stability

- Obtainment, collection, processing of aerospace data as well as its decoding for assessment of action dynamics of natural territorial complex as well as forecast on stability in the regions where pipelines pass through;

- $\quad$ Preparation of special thematic maps for analysis of state of natural territorial water supply complex on the basis of results of aerospace, geodesy-cartography materials processing and interpretation;

- $\quad$ Processing of space-digital illustration by virtue of ERDAS software and creation of database for experimental areas along major pipeline;

- Convert of cartographic materials into vector format and their processing with application programs (for example, ArcGis or Mapinfo);

- Realization of applied information-analytical GIS projects along the different areas of major pipelines requiring special attention.

- $\quad$ Possible and analytical assessment of actually and potentially hazardous state of major pipelines.

In the issue of human impact dimensions, scope of natural environment changes, the rate of changes are very high at the modern period, accordingly the study of these changes on the great territories at the moment of unit of time by land-based research methods is not possible practically. The joint use of modern computer GIS technologies, cartographic methods, remote research methods and traditional study methods of major pipelines, i.e. integration of the mentioned techniques would be the most optimal and efficient modern approaches in space-time aspect for monitoring of eco-condition of water supply system.

On the figures 4 and 5 are demonstrated the preliminary results for creating GIS for Azersu OJSC with the purpose for monitoring of eco-condition of the water supply system.

In the modern conception monitoring is a regular observation system, i.e. control (management) system of the state and displacement dynamics of natural and anthropogenic objects on the basis of program and consists of assuming measures on forecasting (long-term, short-term or operative) of emergency situations as well as probability of occurrence and development of accidents including prior (in advance) determination of events that may occur $[1,2]$. Forecasting of events is provided on the basis of analysis of possible causes as well as resources creating them in the past and at the present period.

It should be mentioned that corrosion of engineering constructions is directly depends on rate of development of natural and natural-anthropogenic processes occurring in the natural and anthropogenic system and the territories where this system is located, major pipeline pass through. Especially, interrelation of major pipelines with physical-geographic environment leads to creation and activation of bog development, karst and heat karst, surface erosion of ravine and soil, crack formation and such other events which cause accidents in the pipelines.

One of the main issues during monitoring of pipelines is a complex assessment of natural and anthropogenic elements. By virtue of it detailed information on each pipe is collected and project is realized. Therefore, upon assessment

which area needs capital repair works or construction or complete change of its parts, necessity for assumption of special defensive measures with a view to provide ecologically safe and stable operation of construction, which areas need determination and performance of works required on the monitoring of pipelines are clarified.

Space information means provides generalized information for solution of number of issues on the remote research of natural and anthropogenic objects.

In general, mathematical model defining the state of water supply natural and technical system is specified in multiplicity of parameters, i.e. n-dimensional multilayer space form - vector layers from geometric point of view. Parameters of system can be figuratively divided into 2 classes: natural and anthropogenic parameters. This implies bringing $\mathrm{n}$-dimensional (parameter) vector of water supply system in 2-dimensional vector, i.e.: natural components - technical constructions. If we indicate this statistical model as time parameter-dependent, we create the dynamic model of the system which enables to follow the state of the system in different time elements. Dynamic model is mathematically written as follows:

$$
\begin{gathered}
Y\left(x_{1}, x_{2}\right)=a_{1} x_{1}(t)+a_{2} x_{2}(t)+c, \\
x_{1}=b_{1} t+b_{0}, \\
x_{1}=b_{1} t+b_{0},
\end{gathered}
$$

$b_{1}, b_{0}-$ are regression coefficients, characterizes function curve inclination and cross point with probability axis, t-time.

\section{CONCLUSIONS}

The territory of the Republic of Azerbaijan has complex physical-geographic, geologic and geomorphic structure, tectonically seismically active. A number of unparallel in the world infrastructure projects are realized in our country for large-scale population on the background of socio-economic progress. One of the most large-scale and important projects are executed by OJSC Azersu: creation of water supply system for protection of human health. It must be noted that assessment and consideration of affect of above mentioned natural factor in the stage of projection and construction of water supply facilities, organization of monitoring by geo-information mapping method of natural and technical system are executed. This requires information support of manufacturing and technological processes. Accordingly, the creation of relevant sphere, Geographic Information System by using digital cartography and geospatial modelling methods is very necessary. 


\section{Solution : The AzersuCIS* Project}

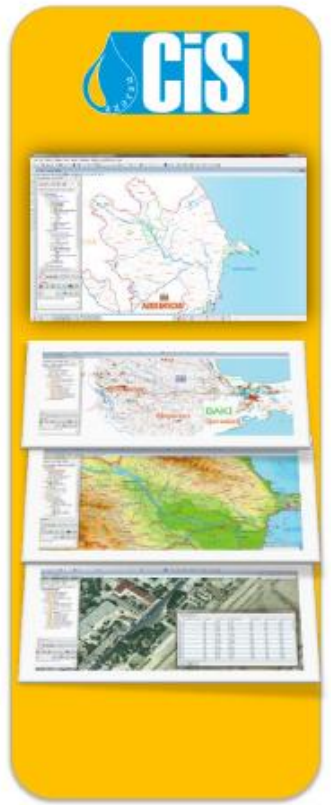

${ }^{*}$ AzersuGIS

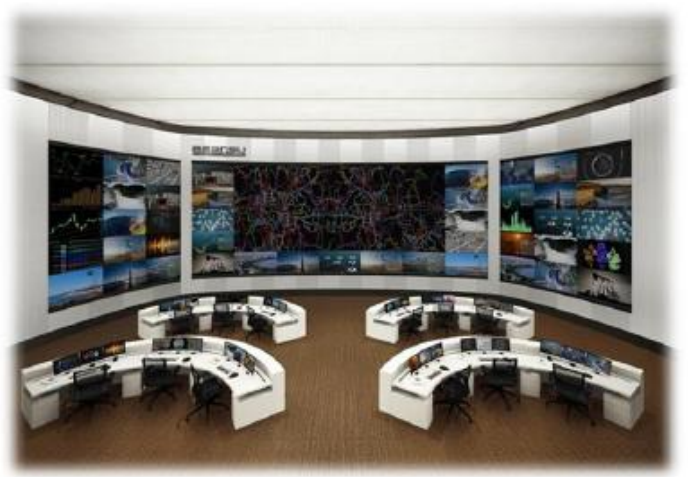

Collect and store infrastructure data in a GIS for better operation and maintanence of the infrastructure system.

The main collaboration platform for the Master Plan, SCADA and the other IT systems.

\section{AzersuCIS Project}

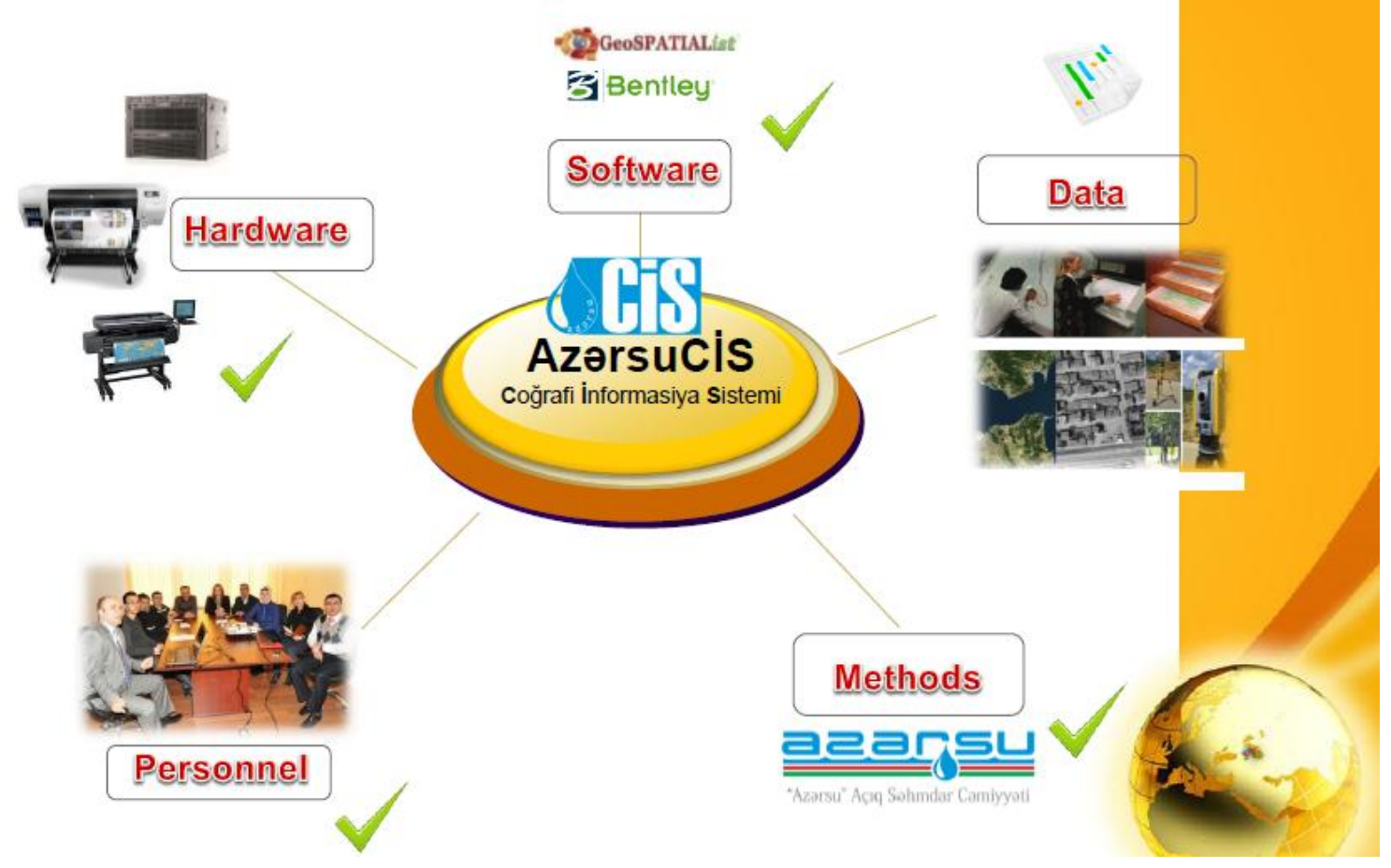

Figure 4. AzersuGIS Project 


\section{G.I.System Analysis of AzersuCIS}
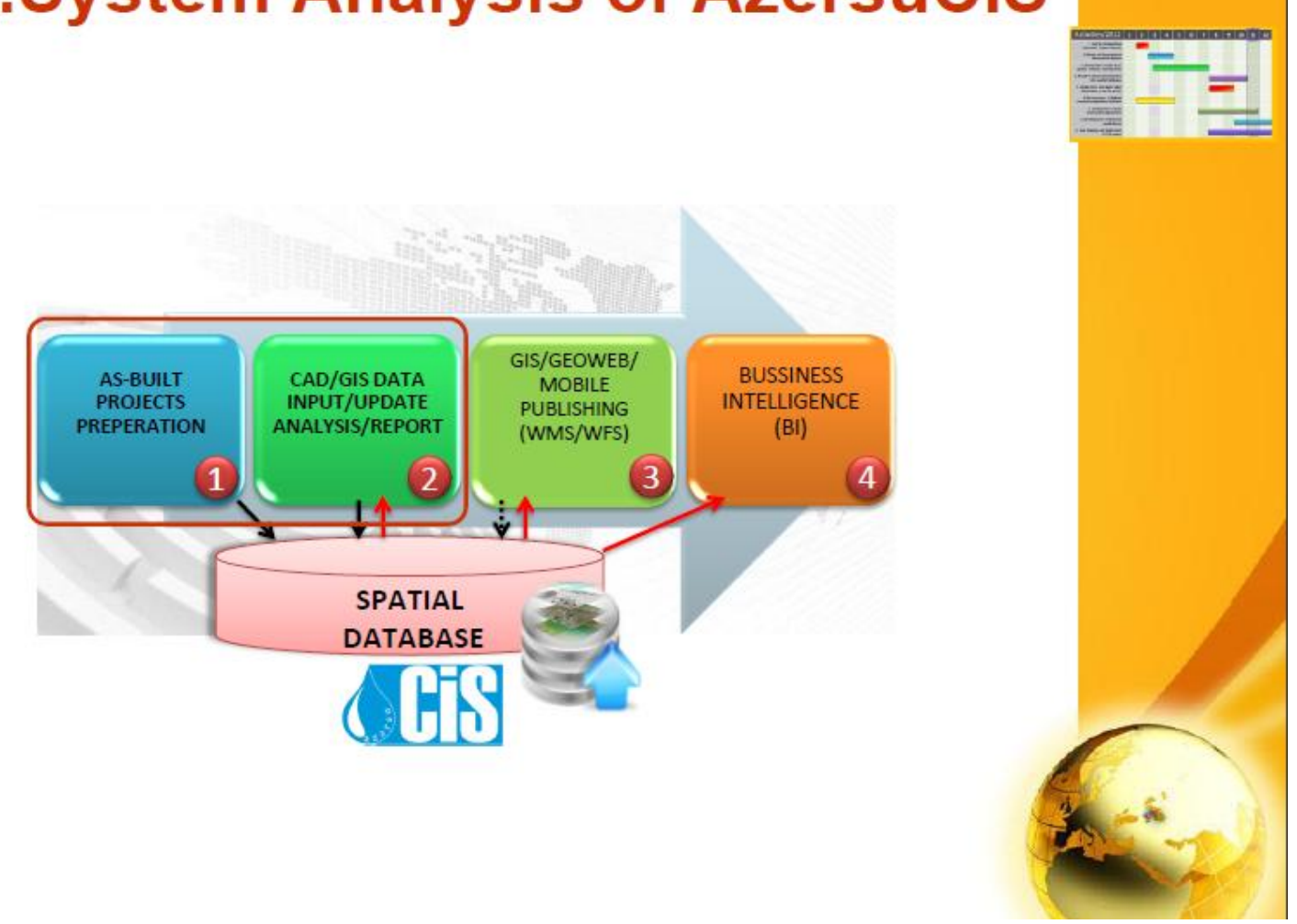

Step : 1

\section{G.I.System Analysis of AzersuCIS}

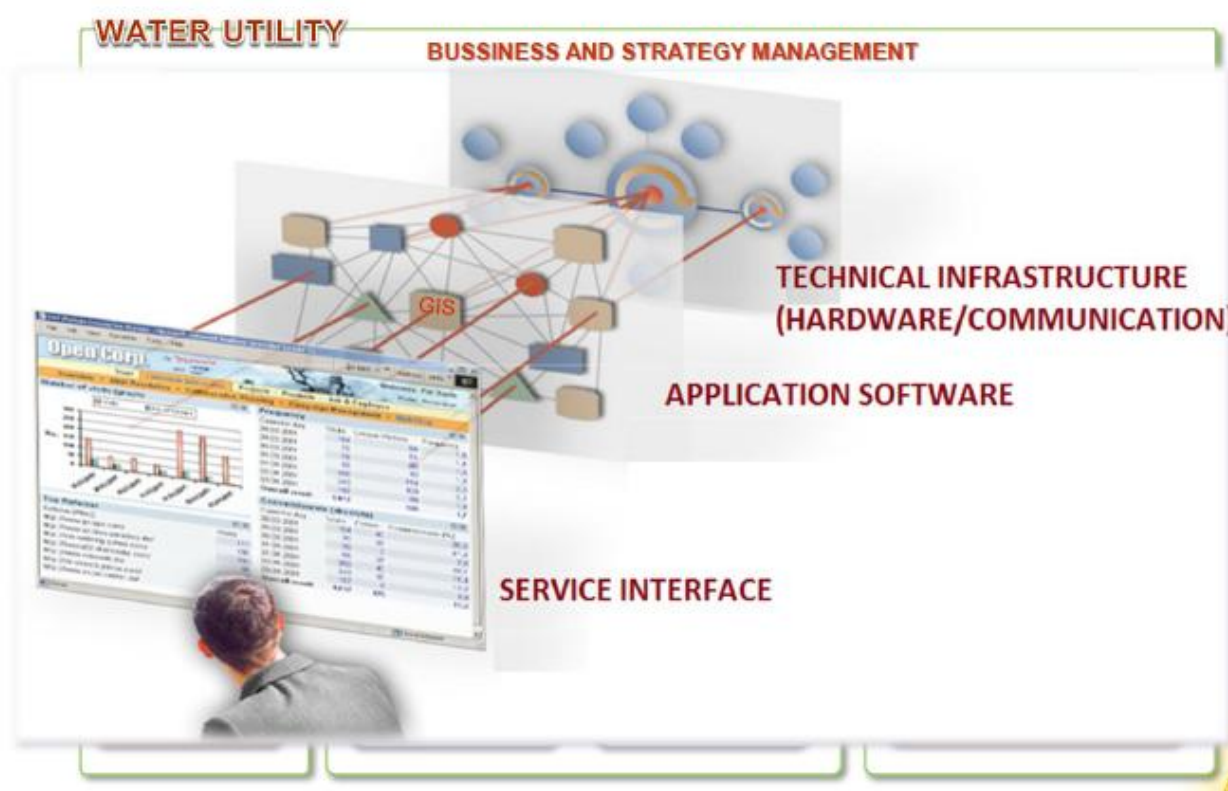

Figure 5.System Analesis of AzersuGIS 
The International Archives of the Photogrammetry, Remote Sensing and Spatial Information Sciences, Volume XL-2, 2014 ISPRS Technical Commission II Symposium, 6 - 8 October 2014, Toronto, Canada

\section{REFERENCES}

Gojamanov, M., 2006a. Geodetic monitoring the location of the offshore objects.Baku.Hydrometeorology and environmental protection, No3, pp. 126-130 (in russian).

Gojamanov, M., 2009. Geodetic maintenance and monitoring works at sea. Moscow-Baku, 104p (in russian). 